\title{
The Des Moines BirthPlace: Iowa's First Birth Center
}

\author{
RENNE ANN CRAMER
}

IN 1980 a small group of Des Moines women founded WomanCare, Inc., with the goal of using that non-profit organization to open and support an out-of-hospital birth center in Des Moines. That goal came to fruition with the creation of the Des Moines BirthPlace, a 1,952-square-foot rental in the "armpit of Mercy Hospital," which founders "converted . . . into a pretty homey place." 1 During the early years of planning, WomanCare founders focused on understanding the potential client base, building clientele through word of mouth, and learning everything they could about the changing fields of certified nurse-midwifery and natural childbirth. Within four years, they had amassed enough funding to rent and outfit the necessary space, conducted

1. Dana Ericson, interview with author, Des Moines, May 2008.

This article is based on archival work at the Iowa Women's Archives, funded by a grant from the State Historical Society of Iowa. It is also based on ethnographic field work with contemporary birth choice groups, particularly Friends of Iowa Midwives, and my participation in and personal conversations at The Big Push national conference in Birmingham, Alabama (June 2009); my participation there was funded, in part, by Drake University's Center for the Humanities and the Provost's Office at Drake University. As well, I conducted interviews with two players in the history of birth centers in Des Moines: Dana Ericson and Carey Ann Ryan. Funding for transcribing and coding those interviews came from an American Political Science Association Small Grant. I gratefully acknowledge the support of each of these grantors. I am also grateful for the anonymous reviewers' support and critique of this article, as well as for suggestions for revision from Marvin Bergman and Professor Robbie Davis-Floyd. They all contributed to a much better article than originally completed; all remaining omissions and errors are my responsibility.

THE ANNALS OF IOWA 71 (Winter 2012). (C) The State Historical Society of Iowa, 2012. 
market research and a consciousness-raising blitz, and hired certified nurse-midwives (CNMs) to staff the center.

Nurse-midwives provided services at the BirthPlace from 1984 until 1991. During its short tenure, the BirthPlace was the site of nearly 250 out-of-hospital births, pre- and post-natal visits for as many women, and hundreds of well-woman exams. ${ }^{2}$ The BirthPlace was a locus of primary care for a small but significant portion of women in Des Moines and the surrounding area. The story of the BirthPlace - its opening, its operation, and its demise - is one of a unique set of local circumstances; it is also the story of a group of Iowa women responding to, and helping sustain, a national movement toward out-of-hospital birth.

This article examines both contexts for the BirthPlace: the national movement toward birth centers as sites of labor and delivery, and the unique opportunities posed by the BirthPlace's location in a capital city with a strong corporate leadership. The founders of the BirthPlace were willing and able to navigate small-business ownership in a niche regional market; in addition, shifting cultures of birth in Des Moines, contextualized within national changes in attitudes toward birth, enabled early success for the center. These aspects of the BirthPlace's development and operation were important for the initial fundraising and client-based successes of the enterprise; they were also significant contributors to the ultimate demise of the center in 1992.

Twenty years later, there is no free-standing birth center in the state, the licensing legislation has been rescinded, and families in Iowa continue to fight for legalization and regulation of certified professional midwifery in order to have more options for out-of-hospital birth. The conditions that enabled the BirthPlace to succeed initially are still present in the state; a close study of its history enables us to understand the contemporary context for birth options in Iowa as part of a continuum of movement in favor of midwifery nationwide.

Thus, this article contributes not only to the history of women in the region - as a study of the organizational foundations of

2. National Association of Childbearing Centers Official Survey of Experience (1990-91), questionnaire completed by Jean Douglas Smith, folder: "Correspondence, 1982-1992," box 1, Des Moines BirthPlace Records, Iowa Women's Archives (hereafter DMBP/IWA), University of Iowa Libraries, Iowa City. 
a consumer-based movement toward options in childbirth but it also sheds light on more recent movements within the state to expand legal and regulated options for out-of-hospital birth. Although it is a case study examining one birth center in a specific region, the article also contributes to women's history in the United States in general, as the BirthPlace was situated within a national context of feminism that sought birth options beyond the medical model and was lauded by national leaders within childbirth communities for its innovative and entrepreneurial approach. This article begins by briefly examining the role of feminism in moving toward options in childbirth; it then turns to a more extended discussion of the BirthPlace and the work done there from 1984 to 1992, before examining the role the BirthPlace played in creating precedent for contemporary politics and possibilities for out-of-hospital birth in the state.

THE GROWTH in the number of birth centers occurred at a specific point in U.S. history (the 1970s-1990s), and it was a particular manifestation of U.S. feminism. That growth was also part of the move toward professionalization of nurse-midwifery as a field of study and practice. ${ }^{3}$

Second-wave feminists emphasized valuing and caring for women's bodies. The publication of the bestselling Our Bodies Ourselves in 1970, along with the movement within feminism to question received medical wisdom, to empower women to "take charge" of their own bodies and value them, contributed to the growth of women's health as a field of medical specialization. In addition, more women were entering the medical profession, specializing within nursing and becoming physicians. Nursing has long been a female-oriented profession, but 1972 marked the first year that more than 10,000 women applied to medical school for training as physicians, and admissions numbers for women have continued to rise since then. ${ }^{4}$ Feminist his-

3. Raymond G. DeVries, Making Midwives Legal: Childbirth, Medicine and the Law (Columbus, OH, 1996); Robbie Davis-Floyd, "ACNM and MANA: Divergent Histories and Convergent Trends," in Robbie Davis-Floyd and Christine Barbara Johnson, Mainstreaming Midwives: The Politics of Change (New York, 2006).

4. Arnold Relman, "The Changing Demography of the Medical Profession," in Gail Henderson, The Social Medicine Reader (Durham, NC, 1994), 263. 
torian Rickie Solinger notes that the publication of Our Bodies Ourselves, along with Barbara Seaman's text, The Doctor's Case against the Pill, "stimulated the feminist/women's health movement, as well as the consumer rights movement," both of which would be of key importance for pro-midwifery organizations and advocates of out-of-hospital birth. ${ }^{5}$

Dana Ericson, one of the founders of WomanCare and the BirthPlace, confirms that the feminist movement's interest in women's health nationwide was part of the political culture in Iowa, as well. "I think really what sparked my interest in women's health was just what was going on in the mid-seventies, which was [the] women's liberation movement. . . . We'd talk about feminist issues. We joined NOW [National Organization for Women]. So that's when I started entertaining going back to school to become an ob-gyn nurse practitioner." Ericson had moved to Des Moines in 1974 and worked as a pediatric nurse while she and her husband, a physician, raised their four children. About the births of those children, she says, "somewhere between the third and the fourth ... I totally lost interest in going back into hospital nursing. And really my interest had been tweaked for women's health." 6

Women's health has long been at the forefront of feminist concerns, even prior to feminism's renaissance in the 1970s. First-wave feminists in the United States, while focusing on prohibition and suffrage, also, by the 1910s and the dawning of the Progressive Era, turned to issues of childbirth and maternity care. As Robbie Davis-Floyd, an anthropologist and leading expert on the history and development of midwifery in the United States, writes, "Early feminists eagerly sought technological hospital birth, in the hope that it would constitute a positive step toward true equality of the sexes through removing the cultural stereotypes of women as weak and dependent slaves to nature." One commonly used medical technology was the induction of so-called "twilight sleep" - caused by the drug scopolamine, which left women with no memory of a birth experience during which they were physically and emotionally out of control. The

5. Rickie Solinger, Pregnancy and Power: A Short History of Reproductive Politics in America (New York, 2007), 176.

6. Ericson interview. 
unanticipated result was that women, rather than receiving respectful and mother-centered care, entered a short-lived but brutal period of hospital birth. Davis-Floyd notes that even though twilight sleep ended in most locations by the 1940s, the medical model of birth continued through this period and, until the 1960s, often included rituals of hospitalized labor and delivery that were demeaning and infantilizing: mandatory pubic shaving, routine enemas, and use of restraints. ${ }^{7}$

Although second-wave feminism's health focus was primarily centered on "women's determination to have access to safe, effective birth control," feminists also increasingly paid close attention to the power differentials between doctors and patients and began to demand "enough information themselves to insist that physicians and other health professionals deal with them as thinking, mature adults." 8 A significant portion of the growing feminist movement focused on access to compassionate pain relief during childbirth without a return to the days of scopolamine. They championed the use of epidurals, which would keep women conscious during labor and delivery but without pain. Davis-Floyd calls this the "technological model" and argues that it became, and remains, the mainstream approach to birth. Those who espouse the technological model do not directly challenge the medical model but demand that it be sensitive to the needs of women, babies, and families. If it is not, families may seek alternative models of care during labor and delivery, models that comport with what Davis-Floyd calls a "humanistic paradigm" of childbirth that seeks to make technological practices in birth "relational, partnership-oriented, individually responsive, and compassionate." Stopping shy of what Davis-Floyd terms the "holistic paradigm," which emphasizes

7. Robbie Davis-Floyd, Birth as an American Rite of Passage (Los Angeles, 2003), 70-71.

8. Solinger, Pregnancy and Power, 176. It is critical to note that feminists of color and women living in poverty often sought reproductive health care that was neither about birthing nor birth control; they sought access to health care that would not leave them unwillingly infertile through sterilization that occurred without their consent. This aspect of reproductive justice was routinely ignored by mainstream feminists of the day. See Jennifer Nelson, Women of Color and the Reproductive Rights Movement (New York, 2003); and Dorothy Roberts, Killing the Black Body: Race, Reproduction, and the Meaning of Liberty (New York, 1998). 
the essential unity of practitioner and client, the "humanistic model," finds its expression in the awareness of a mother's mind-body connection during birth and often is manifest in midwifery relationships in birthing centers and other locations. ${ }^{9}$

Such a model is present in American culture in large part because of an alternative feminist advocacy of natural birth, which focuses on the power of women in birth, the naturalness of the process, and the usefulness of pain in labor. The publication, in 1975, of Ina May Gaskin's Spiritual Midwifery, a collection of birth stories from women laboring and delivering under the guidance of "lay midwives" at The Farm, an intentional community in Tennessee, was a watershed moment in beginning to normalize natural childbirth. ${ }^{10}$ The publication of Gaskin's book, and the activism of midwives and home-birth families across the nation, made out-of-hospital birth a possibility for women seeking alternatives to the medical model.

Few women were willing or able (due to a lack of legal practitioners) to have an out-of-hospital birth on the model promoted by the midwives at The Farm. Nonetheless, women nationwide became interested in natural, drug- and intervention-free birth through techniques such as Lamaze and the Bradley Method. This was especially true of middle-class, educated, urban, white women who had access to Elisabeth Bing's groundbreaking 1967 book, Six Practical Lessons for an Easier Childbirth. As early as the 1960s and '70s, hospitals began to allow, and even embrace, methods of childbirth preparation for labor and delivery that made epidurals less necessary. ${ }^{11}$

Certified nurse-midwifery, as a professional field, was also coming to prominence at this time, after a long nascency. Mary Breckenridge founded the first nurse-midwifery school in the nation, in Hyden, Kentucky, in 1925. With Breckenridge's help, a second nurse-midwifery school was founded in New York City in 1928, but the model was not widely accepted for nearly

9. Robbie Davis-Floyd, "The Technocratic, Humanistic, and Holistic Paradigms of Childbirth," International Journal of Gynecology and Obstetrics 75 (2001), Supplement 1:S5-S23.

10. Ina May Gaskin, Spiritual Midwifery, 3rd ed. (Summertown, TN, 1990). See also Davis-Floyd, "ACNM and MANA."

11. Elisabeth Bing, Six Practical Lessons for an Easier Childbirth (New York, 1967). 
50 more years. Nurse-midwives had to overcome significant medical resistance to their practice, especially from ob-gyn doctors. They also encountered stereotypes regarding the appropriate place and clientele for nurse-midwifery. ${ }^{12}$

A key part of the movement toward professionalization for nurse-midwifery was the establishment, in 1956, of a "maternal and infant health nursing" program in the graduate program at Yale University's School of Nursing, and the continued development of educational standards for nurse-midwifery. ${ }^{13}$ During the 1960s, nurse-midwives consolidated their role in hospital birth, professionalized, and organized - working within the medical model but offering a standard and quality of care very different from those of dominant modes of birth. By the mid1970s, nurse-midwives were ready to challenge the hospital's image as the only (or even best) location for birth. Nursemidwives opened the first free-standing (not affiliated with a hospital) urban birth center in the United States in New York City in 1975 - nine years before the BirthPlace would open in Des Moines. ${ }^{14}$

Birth centers arose as alternatives to both hospital births and births attended at home. Although hospital birth is still the overwhelming choice of most parents, birth centers offer an important alternative for parents who, for many reasons, prefer to deliver in an out-of-hospital environment that is not their home. Some prefer birth center births to home birth because they reside in houses that are not amenable to home birth (such as homes too far from hospital facilities in case of emergency, homes with too many residents to ensure a private birth experience, and homes that are apartments, too close to other apartments for laboring women's comfort). Some parents who want to labor out-of-hospital, but live in states where home birth at-

12. For histories of midwifery, particularly in the United States, see DavisFloyd, "ACNM and MANA"; and Judith P. Rooks, Midwifery and Childbirth in America (Philadelphia, 1997).

13. Davis-Floyd, "ACNM and MANA," 35.

14. Maureen May and Robbie-Davis Floyd, "Idealism and Pragmatism in the Creation of the Certified Midwife: The Development of Midwifery in New York and the New York Midwifery Practice Act of 1992," in Robbie Davis-Floyd and Christine Barbara Johnson, eds., Mainstreaming Midwives: The Politics of Change (New York, 2006), 152. 
tended by a midwife is illegal, have birth center births as their only option (a small minority of these parents will undertake unattended home birth, a potentially dangerous decision). Other parents prefer birth center births because the staff, rather than the family, does all of the work of cleanup and caretaking after delivery. And parents may prefer birth center births to home birth because there is a sense of safety in having a nursemidwife and a more fully staffed and stocked facility than a home. In sum, parents take comfort that birth centers are locations for out-of-hospital birth that replicate a "home-like" atmosphere with access to medical technology in facilities that are near hospitals.

Both nurse-midwives and certified professional midwives, sometimes in partnership with each other, staff such centers. Often they do so because they prefer birth center practice to both home-birth and hospital practices. Birth center practices offer a midwife more professional autonomy than hospital practices do. And in birth centers nurse-midwives can more closely replicate a natural birth process. ${ }^{15}$ Finally, a birth center practice also requires much less travel than a home-birth midwifery practice does and offers the safety and comfort of a known environment for the birth practitioner.

For all of these reasons, some families and midwives, not wanting to labor and work within the hospital environment but uncomfortable with or unable to labor or work in homes, found the birth center an excellent option. As a result, the United States saw a growth in the number of free-standing alternative birth centers from 1970 to 1990. Just as nurse-midwives were engaged in a process of professionalization and development, so too were birth center managers engaging in a process of gaining licensure and professional status and developing niche marketing for their out-of-hospital birth locales. The primary professional organization for birth centers, the American Association of Birth Centers (AABC), was assisted in its founding by the Maternity Care Association, based in New York City and today known as Childbirth Connection, with grant funding from the John A. Hartford Foundation. That organization continues to be a pow-

15. DeVries, Making Midwives Legal, 91. 
erful lobbying arm and information clearinghouse for birth center midwives and consumers.

Research on free-standing alternative birth centers shows that their practices and outcomes tend to minimize intervention during labor and delivery and that they have "outstanding" results in terms of reducing rates of cesarean sections and perinatal death. Davis-Floyd cites a 1989 study of 11,814 birth center births showing a perinatal death rate of 1.3 per 1,000 and a 4.4 percent cesarean section rate, which compares favorably to national cesarean section rates of over 28 percent at the time, a rate much higher than the World Health Organization's recommendation that it not exceed 13-15 percent. ${ }^{16}$ It is difficult to compare maternal and child morbidity rates among hospital, home, and birth center births, because midwives screen home and birth center births for risk and accept only low-risk pregnancies, while hospitals must attend women of all risk levels and thus will always have a higher perinatal death rate. When low-risk hospital births are compared to low-risk birth center and home births, however, perinatal mortality rates are about the same about 1-2 deaths for every 1,000 births. There is, therefore, no additional risk attached to out-of-hospital birth and, proponents of birth centers argue, significantly more comfort for the laboring woman. ${ }^{17}$

In the 1970s and 1980s about 2 percent of American women were giving birth without medication. Half of those were attended by nurse-midwives and other birth professionals, such as doctors, in a hospital setting; the other half were attended by birth professionals in out-of-hospital settings (in homes and free-standing birth centers). ${ }^{18}$ All in all, whether they embraced

16. In 1965 the United States had a C-section rate of 4.5 percent; there has been a steady - and, to many, alarming - rise in that rate to 34 percent in 2009. See childbirthconnections.org for the latest data, and Sela M. Taffel, Paul J. Placek, Mary Moien, and Carol L. Kosary, "1989 U.S. Cesarean Section Rate Steadies - VBAC Rate Rises to Nearly One in Five," Birth 18 (June 1991) 2:73-77. The 1989 study Davis-Floyd cites in Birth as an American Rite of Passage (Berkeley, CA, 2003), is significant because it was the most comprehensive study done on birth centers and the outcomes of birth center births and thus informed the thinking of the founders of the BirthPlace, and its potential clients.

17. Robbie Davis-Floyd, personal communication with author, April 2011.

18. Davis-Floyd, "ACNM and MANA," 41. 
Ina May Gaskin's at-home model, the Lamaze in-hospital but not medicated model, or the out-of-hospital model available in freestanding alternative birth centers, women nationwide, and in Des Moines, were moving toward reclaiming birth as a natural (not medical) process during which women should be respected. As women learned that out-of-hospital birth in low-risk pregnancies was just as safe as in-hospital labor and delivery, even some who were not interested in the politics of their birthing choices became advocates for natural birth in a variety of outof-hospital settings. Nurse-midwives were key actors in the nationwide movement toward accepting unmedicated birth as well as out-of-hospital models; in Des Moines as well, they were the prime movers toward developing a culture that supported birth centers. Interestingly, the development of this culture focused as much on the business community and the growth of the BirthPlace as a small business as it did on the comfort and desires of laboring women.

ATTITUDES in Des Moines during the 1970s and '80s regarding out-of-hospital birth largely reflected national trends. Des Moines had a very conventional North American birth culture; by 1950, 98 percent of recorded births nationally occurred in a hospital, and the 1970s and "80s saw such "advances" in maternal care via epidurals and inductions that the vast majority of women laboring in the United States expected and wanted to experience during hospital birth. In fact, at the time the BirthPlace's founders were organizing its opening, most women birthing in Des Moines, as in other metropolitan areas nationwide, did not want an out-of-hospital birth. That this is true of Des Moines is evident in the results of a survey undertaken by the BirthPlace's founders, asking what women hoped for in childbirth experiences. ${ }^{19}$

Founders sent a "Child Birth Survey" to 300 families whose names were drawn at random from Des Moines Register announcements of births in Des Moines in the first six months of 1985. The 101 surveys that were returned formed part of the

19. All of the Des Moines data reported in this section are drawn from "The Des Moines Birth Survey," folder: "Evaluations and Statistics, 1982-1990" (hereafter E\&S folder), box 1, DMBP/IWA. 
basis upon which the BirthPlace began to market itself. The surveys, which made it possible to compile important demographic data, also help paint a picture of the birth practices and culture in Des Moines a generation ago.

The survey results showed that all or nearly all of the respondents were within the range of normal maternal age (25$42)$, had at least a high school education, were married (97\%), and were privately insured (97\%). Three-fourths of the respondents had at least one child in addition to the baby whose birth had landed them in the newspaper. More than 75 percent were lifelong Iowa residents, and 43 percent had traveled from outside of Polk County to give birth in Des Moines. Des Moines residents who responded were evenly split among the city's four distinct districts: north- and west-side residents were represented in the same proportion as south- and east-siders.

The survey showed a high level of engagement in the prenatal process by these parents. Nearly all (98\%) of the respondents had received regular prenatal care; most $(82 \%)$ had received prenatal care within the first two months of pregnancy; and 77 percent had taken childbirth education classes. Nearly all of the prenatal care was done by an ob-gyn or in a doctor's office $(96 \%)$. No one had received care from a certified nursemidwife.

The survey also asked about the families' use of alternative health practitioners: chiropractors, homeopaths, and herbalists. None of the respondents reported using any alternative health care practitioners. Although use of such alternative practitioners is part of more recent trends in health care delivery, and acceptance of chiropractic and other modalities is still gaining momentum, it is surprising that no family responding to the survey would report using any form of alternative care in 1985. The picture that this portion of the survey paints of Des Moines clients and patients is that of a conventional group of adults - educated, married, and cautious in their health care choices. Additionally, these clients, or patients, had a high level of satisfaction with the health care they did receive: 93 percent of them were "pretty happy" with the way practitioners took time with them to "answer questions in understandable ways" (96\%) and seemed to "understand the families' concerns" (94\%); 98 per- 
cent of respondents were very satisfied or satisfied with their prenatal care.

Almost all of the respondents (98\%) had given birth in a hospital, with 97 percent of the 101 reported deliveries occurring under a physician's care. Seventy-eight percent of the births were routine vaginal births, 5 percent were vaginal with forceps, and 17 percent were accomplished by cesarean section (which is in line with the statewide and national rates for cesarean section at the time). A majority of respondents (81\%) were given drugs for pain relief. Among those women who were medicated during birth, a now shocking 26 percent of the births took place after the woman had received drugs to be "put out" for the duration of the labor and delivery; only 11 percent of women receiving those drugs reported that they had desired or requested them. Nearly 55 percent of the respondents reported receiving drugs to "help them relax" or "relieve pain," about half (46\%) of whom reported desiring those interventions.

The majority of women stayed more than one night in the hospital after delivery and reported a strong desire to extend their stay (69\% of respondents stayed for 3 or 4 days after delivery, and $77 \%$ reported wanting those stays extended). Almost all families (98\%) reported that they were able, during their stays, to interact with their infants at will and felt free to begin parenting as soon as they were able. Hospitals were, by that time, beginning to engage in "family friendly" practices such as "rooming in" and the provision of support to establish breastfeeding; but by no means were these common or universally expected aspects of hospital labor and delivery. The high level of mother-baby interaction reported by these respondents is unusual for the time; it must also be understood within the wording of the question, which stresses that parents could interact "at will" and when they "were able," subjective perspectives that have shifted over time.

The survey portrays a very standard, medicalized picture of labor and delivery. As was probably the case nationwide at that time, most families responding reported that they desired medical intervention in the birth process and that they desired a longer (not shorter) stay in the hospital after labor and delivery. Interestingly, when asked if they were "very satisfied" with the 
way their labor and delivery unfolded, the same families who reported overwhelming satisfaction with their prenatal care were less satisfied with their birth experiences: only 73 percent were "very satisfied" with their labor and delivery care; 25 percent were "satisfied"; and 2 percent were "very dissatisfied." (The nationwide rates of out-of-hospital birth remain steady at 2 percent, an interesting correlation to the rate of dissatisfaction with the hospital delivery process in Des Moines at that time.)

To the founders of WomanCare and the BirthPlace, this survey proved that the medical model had broken down at the point of labor and delivery. Certainly women laboring and delivering in Des Moines hospitals were noticing disconnects between their expectations and their experiences. But not many of the families participating in the survey could imagine an alternative to their experiences. This is clear from their responses to the questions in the fourth section of the survey, which asked families to report on their attitudes about birth. When asked if they agreed that "low-risk pregnancies and deliveries (normal births) need not be managed in a traditional hospital setting," only 11 respondents strongly agreed; 32 somewhat agreed; and 49 respondents either disagreed or strongly disagreed. When asked whether "a person other than a doctor (ex. a certified nurse-midwife: registered nurses with advanced training in maternity care) are capable of providing adequate prenatal care and performing deliveries for low-risk (normal) births," 52 respondents agreed strongly or slightly, and only 37 respondents disagreed slightly or strongly. Significantly, when birth practices implicating maternal autonomy were questioned, the results showed even more willingness to consider alternative models of labor and delivery. When asked if they agreed that "traditional procedures such as strapping mothers to tables, use of stirrups, enemas and routine fluids should be optional and based upon the mutual decision of the mother and person providing care," 73 percent of respondents strongly or slightly agreed.

The survey's final questions turned from experiences and attitudes toward proclivities. In earlier sections of the survey, these parents had overwhelmingly reported that they were "satisfied" to "very satisfied" with their hospital birth experience and doctor-led prenatal care; some also indicated that they 
believed that low-risk births could be managed in other settings. Respondents were also asked about their awareness of out-ofhospital birth centers and their potential use of one. The survey responses show a high level of base knowledge: 68 percent of respondents had heard of birth centers, and 50 percent thought that they were "good ideas." When asked whether "the out-ofhospital care provided by certified nurse-midwives for women anticipating a normal birth would be as good as care provided by a doctor in a hospital setting," 54 percent of respondents said yes, and 46 percent answered no. However, when asked if they would use a birth center for future births, only 19 percent said a definite yes, while 64 percent answered a certain no. Clearly, respondents were more open to the idea of choice, or options, in childbirth for other women and families than they were to seeking those options for themselves.

This attitude of openness to the choices of others dovetails nicely with the strategies employed by many groups seeking to legalize and regulate a broader range of options in childbirth. Many contemporary consumer-led movements for midwifery rely on taglines such as "choice in childbirth" or "safe childbirth options" - stressing that out-of-hospital birth may not be a choice everyone makes but that the choice should be protected and regulated. This attitude of openness to the choices of others also underpins the work of groups that tend to rise up in defense of midwives or to rally around birth centers threatening to close. These "friends of midwives" organizations take a defensive stance in order to safeguard access to choices in childbirth, namely, to give birth out-of-hospital with a trained professional midwife or nurse-midwife.

The consumer group that initially formed in Iowa, Mothers and Others for Midwives (MOMs), did so on this latter model. The group was organized in 1985, first with the goal of supporting the BirthPlace with word-of-mouth referrals and helping to create shifts in the birth culture of the city; later, it was reactivated to try to save the BirthPlace from the financial woes that would eventually cause it to close. MOMs is not currently active in Iowa, but Friends of Iowa Midwives (FOIM) is. FOIM, which originally began as a support and defense organization, has recently (2005) taken on the proactive, offensive strategy of pro- 
tecting a wide range of options in birth and championing legislation to license midwives as certified professional midwives.

In any case, the founders of the BirthPlace took the data from their survey and read it as good news. They interpreted the survey results as showing a desire and need for out-of-hospital birth in the region. In hindsight, we might be shocked by their optimism - the vast majority of survey respondents had, after all, indicated that they were not interested in having an out-ofhospital birth. Rightly or wrongly, founders used the survey to substantiate their statements of need to licensing boards and potential donors and grantors. They also likely used the findings to write and implement their mission statement, which stressed rights, options, and choices: "It is a basic right of all women to have access to information which enables them to make safe choices regarding their health care and to receive respect for the choices they make." 20

LOCAL PRESS reporting on the BirthPlace during the lead-up to its opening and the first years of its operation was almost completely positive. An early article in 1984 stressed that this was a long-term project, deliberately undertaken to mitigate an already occurring phenomenon - unattended home births undertaken by Iowa families seeking to avoid hospital and medicalized births. Reporter Phyllis Bailey wrote, "Planning for the center began in the summer of 1981 when area obstetrical nurses became concerned with the growing number of home births where no trained health-care professionals assisted." A 1984 Des Moines Register article on midwifery, reprinted from the Associated Press, served to normalize midwifery practice and was paired with a piece by Register staff writer Gary Heinlein, whom BirthPlace founders perceived as "very supportive" of their project. ${ }^{21}$

By the year's end in 1985, the BirthPlace's summary report of activities closed on a positive note. The climate for out-ofhospital birth in Des Moines seemed to be shifting to a more accepting stance, largely as a result of BirthPlace staff and founders' public outreach and the favorable stance of the local media.

20. “Mission Statement," folder: “Goals, 1987-1990," box 1, DMBP/IWA.

21. Des Moines Register, 2/1/1984, clipping in box 1, DMBP/IWA. 
In 1986 the BirthPlace received a fair amount of good local press, beginning with an opinion piece in the Des Moines Register that made explicit connections among feminism, choice, family values, and out-of-hospital birth. The BirthPlace's clients, the editorial noted, belong to "a new generation of pregnant women who are childbirth consumers. Not for them the 'twilight sleep' and passive pain of their mothers; they want to be active participants in choosing how and where their children are born. Many of them are older and better-educated than mothers past, and they're not intimidated by a medical degree. They march into obstetricians' offices ready to question and challenge." 22

That editorial was followed in May 1986 by an article titled "The Magic Moment of Giving Birth" and a guest editorial penned by one of the BirthPlace's founders, Dana Ericson. Ericson's piece focused on the work of anthropologist Robbie Davis-Floyd and on what Ericson called the "nature of childbirth," which, she argued, midwives "respect." Ericson, quoting Davis-Floyd, wrote, "The midwife's rituals reflect a belief system that honors woman and her capacity to create life and her ability to bring it forth." Ericson added this from her personal experience: "I've observed many women knowing the eruption of power that comes with bringing life." 23

Notably, a long piece published in the Des Moines Register in October stressed, "At the BirthPlace, the emphasis is on the normal. Customers are called clients, not patients; they address [the midwife] by her first name and are given her home telephone number." The article was balanced, using pullout quotes from both "sides" of the issue. Dr. Albert Mintzer, who was (and remained) against out-of-hospital birth practices, was quoted as saying, "I believe it's a step backward." His quote was paired with a statement from parents who had used the BirthPlace: "Midwifery practice means that you view birth as a normal

22. Des Moines Register, 4/2/1986, clipping in box 1, DMBP/IWA. The level of support in the local press for the BirthPlace is unusual. It is unclear why so much of the Des Moines Register's coverage, by such a wide variety of reporting and editorial staff, would be so favorable. When I spoke with Kathleen Richardson, the reporter who wrote the 1986 editorial and who is now a professor of journalism at Drake University, she was uncertain why the coverage had been so sustained and so positive.

23. Des Moines Register, 5/6/1986, clippings in box 1, DMBP/IWA. 


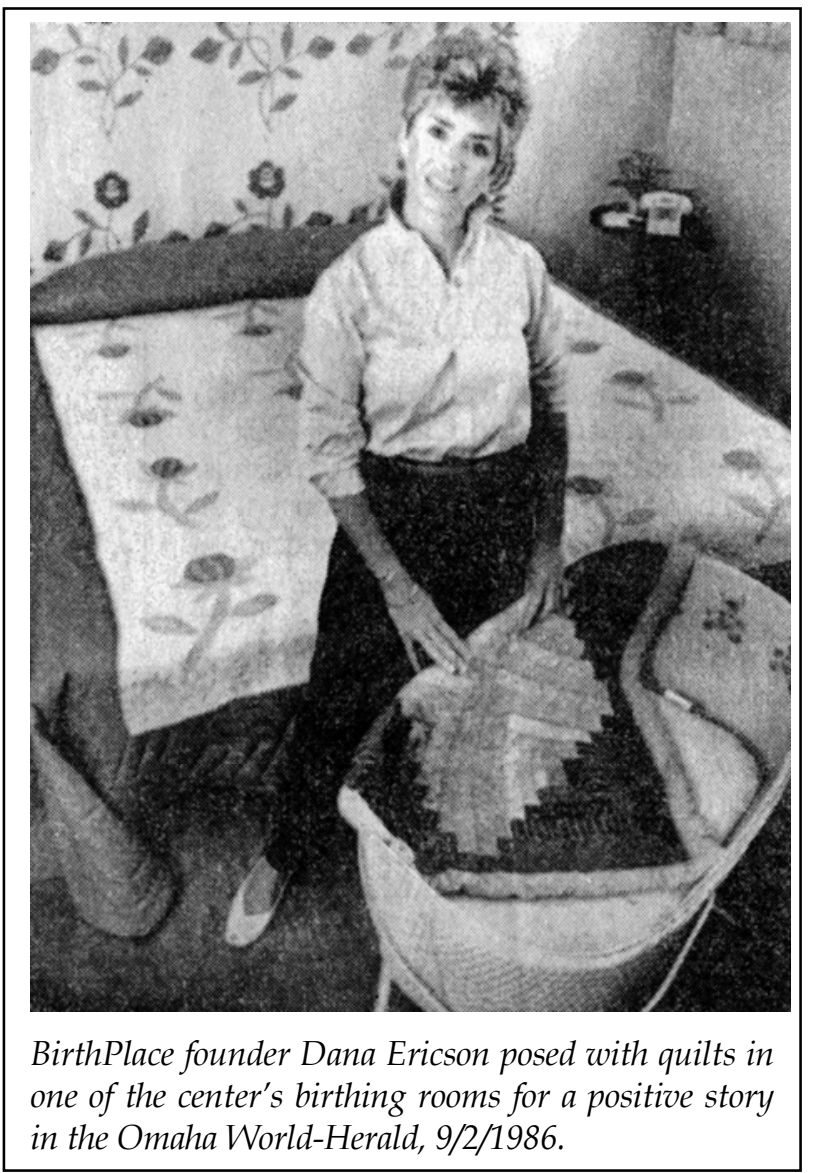

family event." In subsequent issues of the Register, three letters in support of the BirthPlace were published in the editorial section; the Register published no letters expressing opposition to out-of-hospital birth. ${ }^{24}$

At the outset, the Des Moines BirthPlace managed to avoid the active and outright hostility that some birth centers, and many more midwives, encountered. Even the opposition to it, found particularly among hospital staff and personnel, took the form of neglect and obstructive ignorance, rather than antagonistic rhetoric or action. This obstructive ignorance and neglect

24. Des Moines Register, 10/19/1986 and undated clippings, in box 1, DMBP/IWA. 
would eventually have dire consequences for the BirthPlace, when midwives were unable to find physician backup; at the outset of the center's operations, however, neglect was better than vocal hostility, as the lack of a strong and vocal opposition enabled the founders to gather corporate support and foundation grants, as well as clientele, to fund the center's work.

TO AN EXTENT rare among birth centers nationwide, the Des Moines BirthPlace was the beneficiary not only of positive local media coverage but also of financial backing and moral support from local corporate sponsors. Soon after its incorporation, the BirthPlace's board sought to cultivate donations from locally based national businesses such as John Deere and Principal Financial Group, as well as statewide grant makers.

BirthPlace founders took a grant-writing course at Drake University and had initial grant-seeking success that helped build their confidence and their coffers. A $\$ 47,500$ grant from the Northwest Area Foundation came at a key point in 1983, allowing planning to proceed. "It's nice," Ericson reported, "when somebody hands you a check for $\$ 5,000$. And then $\$ 20,000$. And then ... all I had to do really, once that started happening, was invite people to be on our board. So we had the CEO of Pioneer Hi-Bred on our board. . . . We had Elaine Szymoniak [on our board] who was a [state] senator at the time." 25

Even before the doors of the BirthPlace opened, its founders were planning open houses for potential donors, potential clients, and members of the corporate community. They had established a speaker's bureau as early as 1983, and by the time the BirthPlace's doors opened in 1984, they were fielding requests from a wide range of venues. In its first year of operation (1984), BirthPlace staff made 45 individual presentations in a variety of settings, from lectures in local nursing schools and statewide La Leche League conferences to television and radio interviews. That number grew to 55 presentations in 1985, including participation in the local March of Dimes telethon and presentations to a number of religious groups and denominations. ${ }^{26}$

25. Ericson interview.

26. See E\&S folder, box 1, DMBP/IWA. 
A draft of a "1984 Summary of Project Activities" stated, "Business leaders in the community are very interested in and supportive of our project. They have assumed positions on our Board of Directors and promoted our services in other ways. We are preparing a presentation for the Des Moines Business Coalition, a group with a primary objective of lowering employee health care costs." 27 By 1985, the center had a strong roster of corporate and foundation funding, with money from nearly every sector of the Des Moines economy, including Northwestern Bell, Brenton National Bank, Pioneer Hi-Bred International, Meredith Corporation, the Des Moines Chamber of Commerce, Iowa Power and Light, and Bankers Life. Additional significant funding came from the Mid-Iowa Health Foundation, which granted $\$ 20,000$ in 1985 , a grant that was significant not only for the amount of money it provided the BirthPlace but also because it came in the first year of funding by the foundation, which had been started in 1984 to promote community health in mid-Iowa, primarily Polk County, through grant-making activities promoting primary care, children's health, and prevention practices. $^{28}$

Part of the BirthPlace's success in cultivating corporate donors was the sense that the founders and the corporate partners shared a social circle. In an undated fundraising letter to Tom Gould, president and CEO of Younkers Corporate Offices, located in Des Moines, the stated need for carpet in the birth center shared space with a reference to a shared social event, a trick of using olive oil to keep cooked spaghetti from clumping, and the importance of "first impressions" for the birth center's success. As Ericson later put it, "we were very, very network-y." 29

Jean Douglas Smith, chair of the BirthPlace's board of directors, later shared some of this networking savvy with the board of directors of the National Association of Childbearing Centers (NACC; formerly the AABC).

27. "1984 Summary of Project Activities," E\&S folder, box 1, DMBP/ IWA.

28. "1983 Activities," “1984 Activities," "1985 Activities," all in E\&S folder, box 1, DMBP/ IWA.

29. Dana Ericson to Tom Gould, undated, folder: "Correspondence, 1982-1992," box 1, DMBP/IWA; Ericson interview. 
If you want to have some "big names" from the corporate world on your group, you might want to approach Dave Hurd, CEO for the Principal Financial Group. ... Or you might want to ask Roger Brooks, CEO of Central Life Assurance Companies. Roger is incredibly acute, particularly about health care issues He has served on the BirthPlace's Board of Directors and knows something about nurse-midwifery and about out-of-hospital birth. He also knows the intransigence of the current system and the corporate world's role in that. He is a visionary thinker. ${ }^{30}$

WomanCare's founders eagerly cultivated their relationships with business in other ways. Ericson recalled, as the "perfect example," that Central Life Assurance CEO Robert Brooks

invited us in to do "lunch and learns" with his employee groups.... We had ... film days once a month that we could do over the lunch hour at his company.... And the real incentive was that they gave their employees a benefit that if you chose the BirthPlace to pursue the prenatal care and the birth of the baby, you know, it essentially cost them nothing. There was no out-of-pocket anything. There was no deductible. There was no nothing. And then they started listing the families who'd had their baby in the [corporate] newsletter. I mean that's just one example. ${ }^{31}$

Early on, in fact, potentially even more important than corporate financial support was corporate leaders' willingness to include the BirthPlace in medical plans for employees, thus expanding the center's potential client base. ${ }^{32}$ At the time, the Des Moines-based workforce of Principal Financial Group was 75 percent female; presumably many of those women would give birth while employees of the company. Rather than highlighting the center's homelike environment or good outcomes, BirthPlace rhetoric to the corporate community focused, quite early for national political debate, on arguments stressing the low cost and efficiency of BirthPlace births.

30. Jean Douglas Smith to NACC President Kitty Ernst, n.d. (1992), folder: “Correspondence, 1982-1992," box 1, DMBP/IWA.

31. Ibid.

32. Employers who self-insured were able to offer coverage for BirthCenter births; those who purchased group plans from insurance agencies were often able to press for coverage or provide an employer-paid incentive to use the BirthCenter. 
The center's setting and outcomes were certainly important - and figured prominently in advertisements and press releases geared toward attracting clients - but in its appeals to the corporate community of greater Des Moines, BirthPlace representatives usually stressed that they provided efficient delivery of services. Smith believed that birth centers and midwives would be more successful "by allying themselves with the corporate world which is so frantic to contain health care costs at no diminution in quality." In a draft of an "Open Letter to Des Moines Corporate Executives," written by Smith and Ericson but never submitted to the press or sent to business leaders, the BirthPlace founders stressed the poor quality and costineffectiveness of health care nationwide, decried physicians' monopoly over birth, and argued for consumer-led health reform. As Ericson reflected in 2007, "We went to Meredith. We went to Bankers Life. We went to the Des Moines Register. . . You know, we went to big businesses. ... And we sold them on the concept of cost containment. We had to educate them about midwifery. They didn't know anything about it. But boy did they zero in on cost containment." 33

As these comments indicate, even as they sought external support from the business community, the BirthPlace's founders and the midwives they hired stressed their own entrepreneurial spirit. Although it is now standard practice for nonprofit and governmental organizations to follow corporate goal-setting and assessment processes, it was early and unusual for midwives incorporating in the 1980s to do so, especially since many midwives were styling themselves as "counter-cultural" rather than managerial. Yet early BirthPlace documents outline goals, objectives, and evaluation procedures, and show a willingness and even desire to focus on the business side of the center's life, not only its birthing aspects. Goals for 1982, for instance, included

1. formation of Advisory Board Ad Hoc Committees

2. Filing 501(c)(3) tax exempt application

3. Location of potential funding: Foundations

4. Contract with physicians for medical back-up of center

33. Jean Douglas Smith and Dana Ericson, "Open Letter to Des Moines Corporate Executives" (draft), undated (1992), folder: "Correspondence, 1982-1992," box 1, DMBP/IWA; Ericson interview. 
5. File Certificate of Need Application with State Health Dept.

6. Explore State Medicaid reimbursement of nurse-midwives with Department of Social Services

7. Continue to support the passage of the Advanced Registered Nurse Practitioner segment of the Iowa Code of Nursing: (ARNP) Rules and Regulations for licensure of nurse-midwives. ${ }^{34}$

A list of activities for the month of April 1982 showed a similarly wide range of activities for BirthPlace founders: they celebrated National Nurse-midwife Week (April 19-26) by attending a signing ceremony at which Governor Ray proclaimed it Iowa Nursemidwife Week; did two television and three radio interviews; showed the film Daughters of Time and handed out handouts; attended the American College of Nurse Midwives national conference; and achieved federal tax-exempt status and applied for state. ${ }^{35}$ BirthPlace founders were successfully operating on several fronts. They were simultaneously establishing local ties for financial and political support, building a client base, and keeping in touch with the national birthing community.

In 1987 Kitty Ernst, the president of the National Association of Childbearing Centers, the primary professional organization for birth center management, visited Des Moines. Ernst held a consultation with the BirthPlace's board members. During that conversation, as Jean Douglas Smith put it, she "had wrung from all present a commitment to keeping the BirthPlace open and in business." Ernst noted in her comments to the board that "she didn't know of a single birth center in the US which had the consistent support of the corporate community that the Des Moines BirthPlace has." 36 That singularity was a hallmark of the BirthPlace and its success.

However, Ernst also said that they had not exploited this "considerable resource" for all that it was worth, and that they should continue to develop ties with the business community. Unfortunately, the inability to maintain that level of support, combined with staffing problems, contributed to the center's eventual demise.

34. "1982 Activities," E\&S folder, box 1, DMBP/IWA.

35. Ibid.

36. Jean Douglas Smith, "Minutes of Consultation with Kitty Ernst," 11/27/ 1987, folder: "Board of Directors, 1987," box 1, DMBP/IWA. 
ONE UNUSUAL ASPECT of the legal history of the BirthPlace is how eager its founders were to embrace legislation, licensure, and regulation. When the initial business plan was envisioned, midwifery was legal, but there were no laws or regulations governing the operation of birth centers in Iowa: birth centers were a "totally foreign thing" to legislators and regulators. On the one hand, founders of the BirthPlace felt freed up by this lack of regulation. As Ericson later recalled, "First of all, there were no requirements. There were no regs in existence for birthing centers. And there's nothing in the law that governs nurse midwives. . . . We are independent, licensed independent nurse practitioners. So really there isn't anything that could just stop us all. And we were all quite empowered by that because, you know, we had sold the concept to the business community." On the other hand, the BirthPlace's founders recognized almost immediately the liability and risk that accompanied operating in such a lawless environment. BirthPlace founders also felt the need to get a licensure bill passed out of a desire to serve low-income Medicaid clients, as the federal government would not reimburse unlicensed centers. ${ }^{37}$

Ericson recalled the process of getting the licensure bill passed as "an interesting experience." She reflected, "I had never done any lobbying before on a bill, but we had legislators coming in for coffee and doughnut things at our birth center, touring or whatever, for months. . . . We were doing all that. And by George, we got it done." And they got it done on their first attempt - no small feat. The unified support of corporate donors and constituents that they had cultivated was an important factor in their success. Ericson reported that they faced opposition from the Iowa Hospital Association and the Iowa Medical Society. "But you know what? Business was behind us. .. . [We had] the CEO of Pioneer Hi-Bred calling [legislators] saying, 'You know, this is good for our bottom line. It's good for Des Moines.'" In her estimation, corporate support helped the legislative effort tremendously. ${ }^{38}$

37. Ericson interview.

38. Ibid. 
In large part, the BirthPlace's board was successful in securing appropriate legislation because it was seeking a moderate goal: to be brought into the purview of the state for regulatory purposes (not, for instance, to be exempt from regulation). Legislators granted this moderate step, a request to be regulated, with no debate. ${ }^{39}$ Midwifery in the state of Iowa would not be so lucky again.

ALMOST FROM THE BEGINNING of its operations, though, the BirthPlace and its staff faced significant difficulties. Its problems included strained relationships with doctors and hospital staff, financial woes, turnover among the nurse-midwives, and further difficulty convincing nurse-midwives to move to Des Moines to practice. Some of these problems probably should have been predicted, but they were largely unanticipated by the BirthPlace founders. The founders wrote an internal memo in 1985, stating that they had, perhaps, been a bit naive, in their underestimation of the obstacles in their way:

There are only three nurse-midwives practicing clinically in Iowa. Introducing both nurse-midwifery and out-of-hospital births to a conservative community such as Des Moines has been a slow process. We have discovered that satisfied customers provide our best advertising. A major "obstacle" to our growth has been opposition from the medical community.... Physicians have expressed a concern about potential client losses to our service. ${ }^{40}$

The BirthPlace was fortunate to have had a loyal and expanding client base. Many within that client base reported poor relationships with doctors. As part of the standard model for birth center operations, staff at the BirthPlace had to have a good relationship with medical staff in the city; they relied on having hospital privileges and finding doctors willing to work with them. They also needed good relationships in order to ensure

39. The licensure and regulation went into effect in 1988. Although beyond the scope of the present article, it would be fruitful to inquire into the motivations and reasoning for the support of the BirthPlace by legislators and members of the business community. Future research may seek to interview policymakers and business leaders for their perspectives.

40. "1984 Summary of Activities," E\&S folder, box 1, DMBP/IWA. 
good situations when clients needed to transfer into hospital care during or immediately after labor and delivery.

Interestingly, local doctors and nurses did not seem to be overwhelmingly hostile and did not overtly show their disapproval of out-of-hospital birth. The horror stories of bad transfer situations reported in the literature from other parts of the nation were largely absent in Des Moines. ${ }^{41}$ Rather, as one of the founders explained it, members of the local medical community would simply refuse to serve as backup for the BirthPlace. As Ericson put it, "We had one physician who was consistently there for us and he's just now [in 2007] retiring." 42 Part of the problem, even for those physicians who were sympathetic to out-of-hospital births, was the threat of malpractice and vicarious liability suits as well as increased costs of malpractice insurance for doctors who were willing to provide backup. The archives contain internal memos documenting instances when doctors withdrew their backup support and even declined to serve on the BirthPlace's board of directors, citing legal advice from counsel and requests from insurers as their main reasons for doing so. ${ }^{43}$

Even more, hospitals themselves (not just individual physicians) would refuse to interact with BirthPlace midwives and remained steadfast in refusing to grant them the hospital privileges they needed for prescriptions, lab work, and workable transfer relationships. An internal memo in 1985 noted,

Frustrating obstacles were encountered in attempts by the CNMs to obtain clinical privileges at Des Moines hospitals. . . . Applications [for privileges] were submitted in October 1984. The By-Laws

41. Renee Ann Cramer, "Limits of Law in Securing Reproductive Freedoms: Midwife Assisted Homebirth in California," unpublished manuscript presented at the 2009 annual meeting of the Law \& Society Association, on file with author. See also Robbie Davis-Floyd, "Home-birth Emergencies in the US and Mexico: The Trouble with Transport," Social Science \& Medicine 56 (2003), 1911-31; and gentlebirth.org, a web site established and maintained by midwives in California, in part to document difficult transport situations and legal quagmires.

42. Ericson interview.

43. Memo, Jean Douglas Smith to Board and Staff at WomanCare, Inc., 4/7/ 1988, folder: "Board of Directors, 1988," box 1, DMBP/IWA; [Dr.] Mary M. McMahon to Jean Douglas Smith, 11/30/87, ibid. 
at I[owa] L[utheran] H[ospital] are written (and interpreted) to restrict clinical privileges to only those allied health professionals who are employees of either the hospital or a physician enjoying privileges at the hospital. . . . Mercy's denial of clinical privileges was much more vague than ILH. ... A request for clarification has not been satisfactorily answered.

The memo concludes, "It has become apparent that action on our requests for applications, privileges and By-law revisions can be effectively held up for indefinite periods of time." Adding to the obstacles, near the end of 1985 the first two nursemidwives employed by the center resigned before their applications for hospital privileges at Iowa Lutheran were processed. Their reasons for resigning were related to but not limited to the lack of hospital privileges. ${ }^{44}$

One of the unanticipated difficulties the founders of the BirthPlace faced was their limited ability to attract, hire, and retain well-trained nurse-midwives who fit the model of their practice. Nurse-midwives at the BirthPlace had to be entrepreneurial in securing clients and approaching the community. They also had to be diplomatic and appropriately close to the medical establishment; they had to navigate the strong personalities of the board of directors; and, of course, they had to be skilled midwives able to handle a growing volume of practice. Women with the appropriate education, training, and aptitudes would require an appropriate salary. And that proved difficult for a small organization relying primarily on grants and donations. Dana Ericson reports, “We couldn't recruit midwives. The midwives that we had stayed for a year or two and then they would go and then we recruited and recruited." 45 The shortage of midwives was a primary concern in internal communications.

Financial concerns were intimately tied to the inability to hire and retain midwives in three important ways. First, because the center was under financial stress, those administering it were not able to offer premium wages to incoming midwives. The BirthPlace paid total salaries of just under $\$ 44,000$ in 1985 - an

44. "1985 Summary of Project Activities" and "1986 Summary of Project Activities," both in E\&S folder, box 1, DMBP/IWA.

45. Ericson interview. 
amount divided among two full-time midwives as well as parttime secretarial staff. ${ }^{46}$ By 1991, the BirthPlace was advertising individual certified nurse-midwife positions that paid $\$ 40,000$ each - a significant increase in salary but still a difficult draw for qualified applicants who could make more working in a hospital. Nurses in a hospital setting made, on average, \$29,588 nationwide in 1990, but ob-gyn nurses specializing in labor could expect much higher salaries; some estimates for the era put such salaries at between $\$ 40,000$ and $\$ 90,000$ per year. ${ }^{47}$

Second, the midwives being hired by the BirthPlace for wages less than what they could earn elsewhere were being asked to do herculean tasks. Many midwives who chose to practice in birth centers, or as parts of group practice, did so in part because they had family or life obligations that made being the only on-call midwife undesirable or impossible; nurse-midwives at the BirthPlace, meanwhile, were attending a high volume of births with minimal support or time off. In addition, because it was difficult to find physician backup and secure hospital privileges, the job of any midwife hired to work at the BirthPlace was, in part, to facilitate stronger and smoother relationships with an increasingly reluctant Des Moines medical community. For midwives extremely dedicated to the out-of-hospital model, this proved difficult to do. As Jean Douglas Smith wrote in a note to the nurse-midwives employed by the center, "I do have some suggestions for 'wooing' physicians. I agree that this has to be handled subtly, sensitively, diplomatically and very carefully." 48

A combination of these factors - in particular, low pay and a stressful work environment - contributed to the quick burnout experienced by midwives working at the center. As a result, the BirthPlace had to resort to hiring midwives on a rotating basis. This is the third important way that financial concerns were tied to the center's inability to hire and retain nursemidwives. As the BirthPlace lost its full-time residential mid-

46. "1985 Summary of Project Activities," E\&S folder, box 1, DMBP/IWA. The average nursing salary in 1980 was just over $\$ 13,000$ per year.

47. See various documents in folder: "Recruitment, 1991," box 1, DMBP/IWA. 48. Jean Douglas Smith, undated note, folder: "Hospital Privileges, 1984-1990," box 2, IWA/DMBP. 
wifery staff and was consistently unable to attract the candidates it sought to recruit, the directors relied on a cadre of outof-town midwives willing to temporarily relocate for a brief stint in Des Moines. The midwives who applied for such positions came from a wide variety of backgrounds. Some were working in larger city settings and sought a more relaxing pace for a brief time; others came from rural environments and sought access to a higher volume of births. While potentially a boon to the local birthing community's ability to attract highquality practitioners who otherwise would not relocate to Des Moines for a longer period of time, this model ultimately contributed to the center's demise.

This is so for two reasons. First, a steadily rotating staff found it especially difficult to establish working relationships with the medical professionals in the city. More problematic, each traveling midwife would find it difficult to be in Des Moines long enough to establish a relationship with the parents birthing in the center. None of the midwives' rotations lasted an entire 40 -week gestational period, so none was able to be with a client from the beginning of the pregnancy to the birth, let alone through the post-partum, or follow-up, well-woman care. Most families who choose to birth with midwives in an out-of-hospital setting do so in large part because they want a closer relationship with the birth professional attending them; the rotating midwife model made such relationships impossible.

In addition, by the early 1990s, the BirthPlace was beginning to develop a client base that relied heavily on loyal returning families as well as word-of-mouth recommendations from families pleased with their birth experience at the center. Absent a long-term midwife, those referrals were sure to drop off. One could recommend the center, certainly, but it would be impossible to recommend a particular midwife. Regarding this aspect of the rotation model, internal memos note, "The effect on the growth of business is devastating." 49

Finally, in its need to staff the center, the BirthPlace was at the mercy of the financial demands of the midwives rotating in to serve the community. Some were willing to do so for mere

49. Memo, 1986, folder: “Goals, 1987-1990,” box 1, DMBP/IWA. 
relocation costs, others for a low per diem. Some, though, sought their normal fees, often much higher than a full-time residential midwife would have earned at the center.

The model of rotating out-of-town midwives to serve the BirthPlace was born in part from financial necessity - the inability to hire permanent staff at competitive rates. The model in practice ultimately contributed to the center's closing by being an expensive solution to a long-term problem, one that exacerbated the difficulty of developing lasting relationships with doctors, nurses, and birthing families.

THE BIRTHPLACE'S INITIAL SUCCESS in attracting corporate sponsorship also actually may have contributed to its eventual demise. In 1985 client receipts were up substantially from its first year; the BirthPlace earned $\$ 44,576$ from client services in that year. However, the majority of its income $-\$ 45,113$ - still came in the form of contributions and donations. ${ }^{50}$ Even with growing client numbers, the BirthPlace was not operating sustainably absent corporate and foundation support. That was tenable for the first few years of operation, but eventually donors hoping to see sustainability in financial practices began to taper off their contributions.

By 1988, the financial reports showed a stronger ratio of client receipts to other sources, which coincided with an alarming decline in corporate and foundation support. In that year, client receipts made up $\$ 142,200$ out of a total revenue base of $\$ 143,195$. Even though the BirthPlace's directors continued to seek grants and contributions, they were having less success in that regard. Yet their income covered their expenses $(\$ 112,488)$ that year. ${ }^{51}$ The "Year End Business Report," prepared by Jean Douglas Smith in 1988 and delivered to the board, ended on an upbeat note:

I am extremely pleased to say that we ended 1988 with a dedicated staff with high morale. That's quite an accomplishment after who knows how many years of staff-Board friction, staff discontent

50. “Financial Summary 1985," E\&S folder, box 1, DMBP/IWA.

51. “Financial Summary 1988," E\&S folder, box 1, DMBP/IWA. 
over low pay, departing staff, etc. Our two CNMs ... work well together, enjoy one another, and, most importantly for our clients, really have quite different and complementary styles. In May, our CNMs' salaries were increased to a level that is at least satisfactory. ${ }^{52}$

Although things seemed to be looking up financially, the BirthPlace suffered a blow when it lost its two attending midwives and had to move to the rotation method of staffing. The increased expenses of staffing the BirthPlace, the lost clientele caused by the rotation method, and the growing costs of all things associated with running the business brought severe financial and emotional stress to the board and its financial managers. From 1989 until the BirthPlace shut its doors in 1992, communications from board president Jean Douglas Smith to the board were tense. In early 1989, after "some bills" had not been paid for "two to three months," Dana Ericson approached West Bank for a $\$ 5,000$ loan for the BirthPlace and also began facilitating meetings including Smith, the midwife Becky, and community leaders to reinstate some of the corporate and donor funding that "had been keeping the center afloat." 53

At the end of the monthly report for March 1989, Smith noted, "P.S. I failed to mention (how I could have done this, I don't know, because it preys on my mind constantly) that we did not have enough money to pay our employee withholding taxes in a timely fashion." A month later, Smith wrote, "Financial Situation: Things are pretty grim right now. For the first time in my memory, we were unable to meet our payroll last Thursday." She concluded, "I am loathe to sign a contract [with the Teleconnect telephone book] until I have some better indication of whether this place is going to be alive 6 months from now." Summer brought little reprieve. In June 1989 Smith attempted humor when she informed the board, "I wish I had the constitution of Indiana Jones. He, it seems, likes to live on the edge of disaster! I am not so built." 54

52. “1985 Year End Business Report,” E\&S folder, box 1, DMBP/IWA.

53. “Business Report: February to Mid-March 1989," folder: “Board of Directors, 1989," box 2, DMBP/IWA.

54. Ibid.; "Monthly Business Report-May, 1989"; "Business Report," 4/16/ 1989; Smith to Board, 6/5/1989; all in folder: "Board of Directors, 1989," box 2, $\mathrm{DMBP} / \mathrm{IWA}$. 
The board of directors met in emergency session in September 1989, with the sole agenda item of "consideration of the dissolution of WomanCare, Inc. and closing the BirthPlace." In her memo calling the meeting, Smith wrote, "The weight of the financial situation is such that our options appear to be limited to either the closing of our doors or finding a hospital who would like to take over our operations." 55 The board met and decided to keep the center in operation, but its fortunes did not improve. An October 12 letter from Smith to the board showed her to be particularly discouraged. "As you know, at the Board meeting, I was very hopeful that we would generate a contribution from the Des Moines Clearing House (bank presidents), but that did not materialize. We received a letter last week saying that the group had voted not to support us. It was a blow to me, both in terms of my own reading of the situation and in terms of our financial condition." 56

By sheer force of will and the rallies of a concerned and aware parents' group - Mothers and Others for Midwives (MOMs) - the BirthPlace continued to operate for two more years. But its financial problems continued, and the center operated on a nearly month-to-month budget, often with a deficit. In July 1991 Smith wrote, "Cash flow analysis indicates that, at our current level of business ... we are going to be in big-time deficit (around $\$ 28,000$ ). However, by the end of December, we should be relatively okay (only $\$ 4,500$ in the red). The Board seems to think this is handle-able." 57

The BirthPlace might have been able, eventually, to find a way around the financial problems it faced; those difficulties, however, were compounded by lack of doctor support and the need to rely on a rotation of midwives. These three factors (poor finances, lack of midwives, and missing physician support) eventually conspired to close the center down. One of its founders tells the story this way:

55. Smith to Board, 8/31/1989, ibid.

56. Smith to Board, 10/12/1989, ibid.

57. Smith to Patricia A. Cottrille, D.O., 7/31/1991, folder: “Recruitment, 1991," box 1, DMBP/IWA. 
And really what took us down was we were ... existing in that last year on [rotating] midwives. ... But we were able to recruit finally a midwife from Phoenix who claimed she'd never worked at the hospital but she'd wanted to take a shift. And we couldn't find anybody else, so we were like, "Well, here's a midwife who wants the job, so I guess we're fine with it." She, by the time we got her here and really spent time with her, we found out she was so fearful. ... It was so disappointing. . . She was afraid of her shadow. She was afraid of being in the birth center. She was transferring people out right and left. She was constantly calling [the doctor] for this and that. ... I remember the morning we were up there scrambling, working, and the phone rang and it was [the doctor]. And he said, "Dana, I'm pulling the plug. I can't do this anymore. Your midwife is making me nuts." And I had the phone in my hand and I put my hand over the bottom and I said to Jeannie [Smith, the executive director], "It's [the doctor]. He's backing out." And I looked at her and she looked at me and I said, "I understand, we'll be in touch." He goes, "Yeah, I'm sorry. I'm sorry honey, but you know what, I just can't take her." [laughter] . . So I hung up the phone and Jean and I looked at each other and that little front office, and we just said, "That's it. That's it. . . We're closing this sucker down." So in thirty days, we closed it. ... We found everybody a provider. We got everybody transferred. We got everybody whatever and we shut down. Oh and then there was an outrage from the community that it had been closed. .58

After years of financial stress and an unsustainable staffing model, a doctor's unwillingness to continue the relationship was the final straw. After years of planning and strategizing, the Des Moines BirthPlace was closed abruptly.

THE DES MOINES BIRTHPLACE was open for only five years and has been out of operation for nearly 20, yet its legacy and residual effects are significant. Its founders remain active in the birth culture of Des Moines and the region. The past two decades in particular have seen an increased presence of out-ofhospital midwives in Des Moines. Whereas only one certified nurse-midwife operated in the state of Iowa as a whole in 1982 (in a Burlington hospital), in 2012 the city of Des Moines alone

58. Ericson interview. 
has four certified nurse-midwives in home-birth practice, and a roster of nurse-midwives attend births in the city's hospitals. In addition, there is a growing and lively consumer-based movement in support of midwifery, as well as a continued movement toward licensing and regulating out-of-hospital birth providers.

Within a decade of the BirthPlace's closing, Carey Ann Ryan, a nurse-midwife who had moved to Des Moines to be part of the birth center movement, opened Almost Home, a birth center in Des Moines's Ingersoll neighborhood. Ryan came to Des Moines knowing the cultural understanding of birth in the city and the financial challenges the BirthPlace had faced. When asked why she chose Des Moines, given those obstacles, she answered, "Birth centers are still illegal in Illinois. I went to school specifically to work in a birth center." 59 Although Iowa's state legislature repealed birth center licensure in 2002, birth centers remain legal, governed by national accrediting standards from the Commission on Accreditation of Birth Centers. For Ryan, the presence of a previous birth center, as well as legislative openness to industry regulation, made Des Moines an attractive place to relocate. Methodist Hospital objected to the license for Almost Home. The birth center was not needed, it said, because it already provided similar services. Nonetheless, the center was permitted to open in 2003. Almost Home operated as a birth center from 2003 until 2007; the building now sits empty and for sale.

Mothers and Others for Midwives (MOMs), which began in support of the BirthPlace and later offered financial and moral reinforcement for Almost Home, continues to be present in Des Moines midwifery politics, though more quietly. Other organizations have grown to take on its roles of educating consumers, providing support, and rallying in defense of midwives. The Des Moines chapter of the International Cesarean Section Awareness Network (ICAN), devoted to decreasing unnecessary cesareansection births, is particularly active in the city.

ICAN members are often allied closely with three Des Moines-based parenting groups that stress natural birth: Holistic Families Network, the local chapter of La Leche League

59. Carey Ann Ryan, interview with author, Des Moines, January 2008. 
(LLL), International, and the Iowa chapter of Attachment Parenting International (AP-I Iowa). These organizations have overlapping membership with a fourth, more recent manifestation of support for out-of-hospital birth in the state: Friends of Iowa Midwives (FOIM). FOIM, with chapters throughout Iowa, works to promote awareness of birth alternatives while supporting midwives and home-birth families. FOIM is the primary organization in a push reinvigorated in 2008 and steadily gaining momentum to promote legislation to legalize and regulate the practice of Certified Professional Midwifery in Iowa. Certified Professional Midwives (CPMs) are midwives without nurse-midwifery training who pass a rigorous exam after several years of apprenticeship and training. Currently, CPMs are legal and licensed in 26 states, but it is still not possible to get licensed as a CPM in Iowa - one of eight states with active campaigns to achieve legal status and regulation for CPMs. ${ }^{60}$

The movement to pass legislation regulating and licensing CPMs has its genesis in the successful movement, undertaken by the founders of the BirthPlace, to open, legalize, and regulate birth centers in Iowa. The BirthPlace was initially successful because of its founders' ability to network with local business leaders and make a compelling case for corporate sponsorship of the endeavor. To an extent unprecedented in other birth centers of the period, the BirthPlace relied on corporate goodwill and financial support, which enabled the center to be initially successful but ultimately contributed to its demise.

The BirthPlace founders described themselves and their midwife employees as "entrepreneurial" and "professional." Modern midwifery for out-of-hospital birth stresses the same approach. Nationwide, midwives are eschewing the granola, hippie, counter-cultural persona for one that telegraphs "modern," "capable," and "professional." 61 Iowa midwives are a diverse group, even among those who support FOIM and the message of licensing, but the message of professionalism and modernity carry weight at the Capitol.

60. For links to current state efforts and midwives' current legal status, see the North American Registry of Midwives website at www.narm.org.

61. Personal communications and field notes, Big Push meeting, a national strategy session of midwifery consumers and activists, Birmingham, AL, 2009. 
In these regards, as well as in the continued consumer base supporting options for childbirth in the state, the vision of the founders of WomanCare and the Des Moines BirthPlace lives on in central Iowa. That vision is likely to come to fruition in an even more vibrant and family-friendly birth culture in the state, with increased options for consumers seeking to make informed choices about childbirth. 